\title{
Dissociation between Light-Induced Phase Shift of the Circadian Rhythm and Clock Gene Expression in Mice Lacking the Pituitary Adenylate Cyclase Activating Polypeptide Type 1 Receptor
}

\author{
Jens Hannibal,, Francoise Jamen, ${ }^{2}$ Harriette S. Nielsen, ${ }^{1}$ Laurant Journot, ${ }^{2}$ Philippe Brabet, ${ }^{2}$ and \\ Jan Fahrenkrug'1 \\ ${ }^{1}$ Department of Clinical Biochemistry, Bispebjerg Hospital, University of Copenhagen, DK-2400 Copenhagen, Denmark, \\ and 2Unité Propre de Recherche 9023, Centre National de la Recherche Scientifique, 34094 Montpellier Cedex 5, France
}

\begin{abstract}
The circadian clock located in the suprachiasmatic nucleus (SCN) organizes autonomic and behavioral rhythms into a near $24 \mathrm{hr}$ time that is adjusted daily to the solar cycle via a direct projection from the retina, the retinohypothalamic tract $(\mathrm{RHT})$. This neuronal pathway costores the neurotransmitters PACAP and glutamate, which seem to be important for light-induced resetting of the clock. At the molecular level the clock genes $m$ Per1 and mPer2 are believed to be target for the light signaling to the clock. In this study, we investigated the possible role of PACAP-type 1 receptor signaling in light-induced resetting of the behavioral rhythm and light-induced clock gene expression in the SCN. Light stimulation at early night resulted in larger phase delays in PACAP-type 1 receptor-deficient mice
\end{abstract}

In mammals, autonomic, endocrine, and behavioral rhythms are generated by a master clock located in the hypothalamic suprachiasmatic nuclei (SCN) (Klein et al., 1991). To maintain synchrony with the solar day-night cycle, the clock is adjusted (entrained) by light through a monosynaptic pathway originating from a subset of retinal ganglion cells, the retinohypothalamic tract (RHT) (Moore and Lenn, 1972; Johnson et al., 1988; Levine et al., 1991; Moore et al., 1995). Our knowledge on the molecular machinery driving the endogenous clock has until recently been limited, but identification of components of the "molecular clock" participating in autonomous transcriptional/translational feedback loops have shed light on parts of this complex regulatory mechanism (for review, see Dunlap, 1999; King and Takahashi, 2000). How light entrains the clock is, however, not fully understood. The clock genes mPer 1 and mPer2, which show circadian expression within the SCN, have been attributed a role in lightinduced resetting of the mammalian circadian clock caused by rapid induction of both genes after light stimulation at night (Albrecht et al., 1997; Shigeyoshi et al., 1997; Zylka et al., 1998; Akiyama et al., 1999; Yan et al., 1999; Field et al., 2000). A

\footnotetext{
Received Dec. 27, 2000; revised March 26, 2001; accepted April 12, 2001.

This work was supported by The European Commission (BIO-98-0517), The Danish Biotechnology Centre for Cellular Communication, The Danish Neuroscience Program, and Danish Medical Research Council Grant 9702202. The skillful technical assistance of Lea Larsen and Anita Hansen is gratefully acknowledged.

Correspondence should be addressed to Dr. Jens Hannibal, Department of Clinical Biochemistry, Bispebjerg Hospital, Bispebjerg Bakke 23, DK-2400 Copenhagen NV, Denmark. E-mail: J.Hannibal@inet.uni2.dk.

Copyright (C) 2001 Society for Neuroscience $0270-6474 / 01 / 214883-08 \$ 15.00 / 0$
}

$\left(P A C 1^{-1-}\right)$ compared with wild-type mice accompanied by a marked reduction in light-induced $m$ Per1, mPer2, and c-fos gene expression. Light stimulation at late night induced mPer1 and c-fos gene expression in the SCN to the same levels in both wild type and $P A C 1^{-1-}$ mice. However, in contrast to the phase advance seen in wild-type mice, $P A C 1^{-1-}$ mice responded with phase delays after photic stimulation. These data indicate that $P A C 1$ receptor signaling participates in the gating control of photic sensitivity of the clock and suggest that mPer1, mPer2, and c-fos are of less importance for light-induced phase shifts at night.

Key words: retinohypothalamic tract; suprachiasmatic nucleus; clock genes; knock-out; mouse; light entrainment support for this notion is the observation that the use of antisense oligonucleotide blocks mPer1 mRNA transcription, light-induced phase shift of running wheel activity, and glutamate-induced phase shift of neuronal firing activity (Akiyama et al., 1999).

Pituitary adenylate cyclase activating polypeptide (PACAP), a member of the vasoactive intestinal polypeptide (VIP)-secretinglucagon family of neuropeptides (Arimura, 1998), is located in a small population of retinal ganglion cells constituting the RHT (Hannibal et al., 2001). PACAP is colocalized with glutamate in the RHT (Hannibal et al., 2001). In nanomolar concentrations, PACAP phase shifts the endogenous rhythm and induces per gene expression in the SCN similar to light (Harrington et al., 1999; Nielsen et al., 2001) whereas micromolar concentrations of PACAP modulate glutamate-induced phase shift (Chen et al., 1999) and Per1 and Per2 gene expression (Nielsen et al., 2001). Three types of high-affinity G-protein-coupled receptors for PACAP have been cloned: the PACAP preferring type 1 (PAC1) receptor (Spengler et al, 1993) and two VIP/PACAP preferring type 2 (VPAC1 and VPAC2) receptors (Harmar et al., 1998). Both PAC1 (Hannibal et al., 1997) and VPAC2 (Lutz et al., 1993) receptors are expressed in the SCN but so far, most findings indicate that the $P A C 1$ receptor is responsible for PACAP signaling to the circadian system (Hannibal et al., 1997; von Gall et al., 1998; Kopp et al., 1999).

The present study shows that in mice lacking the $P A C 1$ receptor, light stimulation causes a dissociation between photic phase shifting of the circadian rhythm and induction of clock gene expression in the SCN. Our findings indicate that $P A C 1$ receptor signaling participates in the gating control of photic sensitivity of the clock and suggest that mPer1, mPer2, and c-fos are of less importance for light-induced phase shifts at night. 


\section{MATERIALS AND METHODS}

Animals. Males from an $\mathrm{F}_{1-} \mathrm{F}_{4}$-crossbred strain $(129 / \mathrm{SvXC57BL6/J)}$ of PAC1-receptor mutant mice were used (Jamen et al., 2000). Animals were maintained in a $12 \mathrm{hr}$ light/dark (LD) cycle with food and water ad libitum. Experiments were performed according to the principles of laboratory animal care (Law on animal experiments in Denmark, publication number 382, June 10th, 1987).

Behavioral analysis. Mice (age 6-10 weeks at the beginning of the experiments) were housed in individual cages equipped with a running wheel in ventilated, light-tight chambers with controlled lightning. Wheel-running activity was monitored by an on-line personal computer connected via a magnetic switch to the Minimitter Running Wheel activity system (consisting of QA-4 activity input modules, DP-24 dataports, and Vital View data acquisition system, version 2.19; MiniMitter Company, Sunriver, OR). Wheel revolutions were collected continuously in 10 min bins. Animals were entrained to a $12 \mathrm{hr}$ LD cycle (lights on at 7:00 A.M., lights off at 7.00 P.M.) for at least 14 d. Free-running period $(\tau)$ was assessed during days $4-18$ in constant darkness (DD) using Active View software version 1.2 (MiniMitter Company). To determine the light-induced phase shift of locomotor activity, animals in their home cages were moved to another room and exposed to a $30 \mathrm{~min}$ pulse of white light (>300 lux) at two different circadian times (CTs) 16 and 23; $n=7-10$ of each genotype) at which CT12 was designated as activity onset. The CT times were determined according to the equation by Daan and Pittendrigh (1976a). Three wild-type and three $P A C 1^{-1-}$ mice were also exposed to light at CT2, 6, 10, 14, and 20 to obtain a full phaseresponse curve (PRC). Light-induced phase shift amplitude was derived from regression lines drawn through the activity onset of at least $7 \mathrm{~d}$ immediately before the day of stimulation and $7 \mathrm{~d}$ after reestablishment of steady-state circadian period after stimulation (Chen et al., 1999).

In situ hybridization histochemistry. In situ hybridization was performed as previously described (Hannibal et al., 1997). cRNA probes were prepared using ${ }^{33} \mathrm{P}-\mathrm{UTP}$ and cDNA of the rat $P A C 1$ receptor (Hannibal et al., 1997), rPer1, and rPer 2 probes (Nielsen et al., 2001). The mouse $c$-fos cDNA (pTRI-c-fos/exon4-Mouse probe template) obtained from Ambion (Austin, TX) was prepared using T3 polymerase generating a cRNA probe of 279 bases. Control sections were hybridized with the corresponding sense probes, which gave no specific signals. Wild-type and $P A C 1^{-1-}$ mice $(n=6-8$ in each group) kept in $12 \mathrm{hr}$ LD were decapitated at zeitgeber time (ZT)6, ZT17, and ZT24 (in dim red light, $<3$ lux). For light-stimulation experiments, animals received a $30 \mathrm{~min}$ pulse of white light ( $>300$ lux) at ZT16 and ZT23 and were killed (in dim red light, $<3$ lux) $60 \mathrm{~min}$ after the initiation of light exposure (ZT17 and ZT24). We cut $12-\mu$ m-thick coronal brain sections through the SCN from each animal on a cryostat on five consecutive gelatin-coated slides. From each animal this included a total of 20 sections through the rostrocaudal SCN, representing four different levels of the SCN on each slide. A slide from each animal was hybridized under identical conditions with ${ }^{33} \mathrm{P}$ labeled rper1, rper2, and c-fos antisense cRNA probes, respectively. After hybridization and washing, the slides were exposed to Amersham Hyperfilm (Amersham, DK) for 1-2 weeks. Autoradiograms were quantified using an image analysis system (Q500MC Image Analysis System version 2.02A; Leica Cambridge, UK), and grain densities were converted to disintegrations per minute per gram of wet weight using ${ }^{14} \mathrm{C}$ standards as references (Amersham, DK) as described previously (Hannibal et al., 1995a). The level of mRNA of each animal was quantified corresponding to the retinorecipient zone of the SCN by measuring positive hybridization signals in the bilateral SCN, which included four sections through the rostrocaudal SCN, and the calculated mean of these measurements from each of six to eight animals was used to calculate the group mean and SEM. As reported, gene expression of Per1 and Per2 is induced by light in this part of the SCN of rats and mice (Albrecht et al., 1997; Shigeyoshi et al., 1997; Yan et al., 1999). Measurements obtained from the individual sections were corrected for nonspecific background by subtracting grayscale values from neighboring areas (the optic chiasma) considered free of positive hybridization. Thus, the sections served as their own internal standards. The changes in expression between the mRNA levels of the control groups and the stimulated groups were presented in disintegrations per minute per gram according to the ${ }^{14} \mathrm{C}$ standards.

Immunohistochemistry. PACAP immunoreactivity in the mouse SCN was investigated in wild-type and $P A C 1^{-1-}$ mice ( $n=3$ of each group). The mice were fixated by perfusion through the heart at ZT6 in Stefani's fixative and cryoprotected and cut in a cryostat in $40-\mu \mathrm{m}$-thick freeflowing sections, as described previously (Hannibal et al., 1997). PACAP
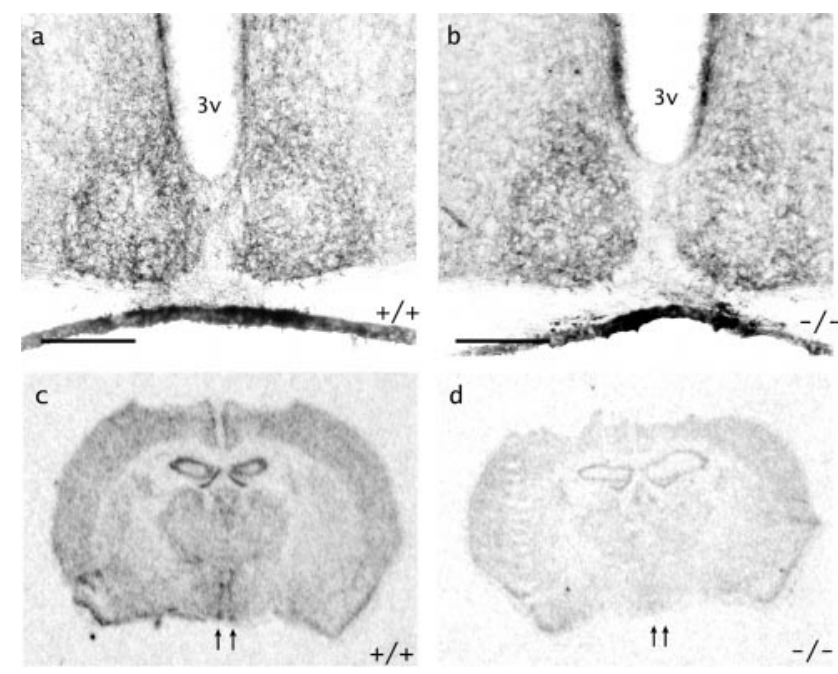

d

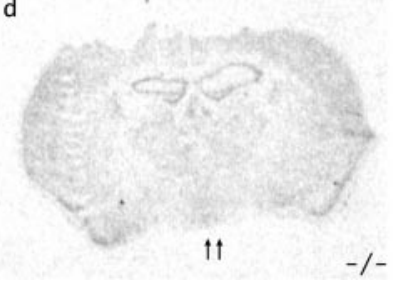

Figure 1. PACAP and $P A C 1$ receptors in the SCN. Photomicrographs showing PACAP-immunoreactive nerve fiber in the SCN of wild-type $(a)$ and $P A C 1$ receptor-deficient mice $\left(P A C 1^{-1-}\right)(b)$. In situ hybridization using a ${ }^{33} \mathrm{P}$-labeled rat cRNA $P A C 1$ receptor probe on a coronal brain section at the level of the SCN of wild-type $(c)$ and $P A C 1^{-1-}$ mice $(d)$. Arrows indicate the positive $(c)$ and negative $(d)$ signal for $P A C 1$ receptor expression in the SCN. 3v, Third ventricle. Scale bars, $100 \mu \mathrm{m}$.

was visualized using a specific monoclonal mouse anti-PACAP antibody characterized previously (Hannibal et al., 1995b) and a mouse on mouse immunodectection kit (Vector Laboratories, Burlingame, CA) combined with ABC-tyramide-DAB staining (Fahrenkrug and Hannibal, 1998). As controls, sections were incubated with antibodies preabsorbed with PACAP38 $(20 \mu \mathrm{g} / \mu \mathrm{l})$, which abolished all staining.

Statistical analysis. Data are presented as mean \pm SEM. Mann-Whitney $U$ test (using GrapPad Prism, version 3.0 software) was used to determine significant differences between values from stimulated and control groups. $p<0.05$ was considered statistically significant.

\section{RESULTS}

\section{PACAP immunoreactivity in the SCN of PAC1 receptor-deficient mice}

Immunohistochemical analysis of SCN sections revealed that the number, distribution, and staining intensity of PACAPimmunoreactive nerve fibers in the SCN of wild-type and $P A C 1^{-1-}$ mice did not differ (Fig. $1 a, b$ ), indicating no gross anatomical differences of the RHT between the wild-type and homozygous littermates. As expected, the wild-type mice but not the $P A C 1^{-1-}$ mice expressed $P A C 1$ receptor $\mathrm{mRNA}$ in the SCN (Fig. 1c,d).

\section{Circadian rhythmicity in PAC1 receptor-deficient mice}

Behavioral analysis of running-wheel activity showed that wildtype, $P A C 1^{+/-}$, and $P A C 1^{-/-}$mice were able to entrain to a 12 hr LD cycle. When transferred to constant darkness, wild-type and $P A C 1^{+/-}$mice displayed the same period length $(\tau)$, whereas $\tau$ of the $P A C 1^{-1-}$ mice was slightly, although significantly shorter, than the wild type $(23.3 \pm 0.1$ vs $23.7 \pm 0.1 \mathrm{hr})$ (Fig. $2 a-d)$. The clock genes mPerl and mPer 2 are expressed in the SCN with a clear circadian rhythm (Zylka et al., 1998). Consequently, we analyzed the expression of mPer1 and mPer2 using quantitative in situ hybridization at three circadian time points (ZT6, ZT17, and ZT24) (Table 1). Except for a modest but statistically significant higher $m P e r 1$ gene expression in $P A C 1^{-1-}$ mice at $\mathrm{ZT} 24$ no differences in the level of mRNA for the per genes were observed between wild-type and $P A C 1^{-1-}$ animals during LD conditions. No difference was observed in the regional distribution of per 

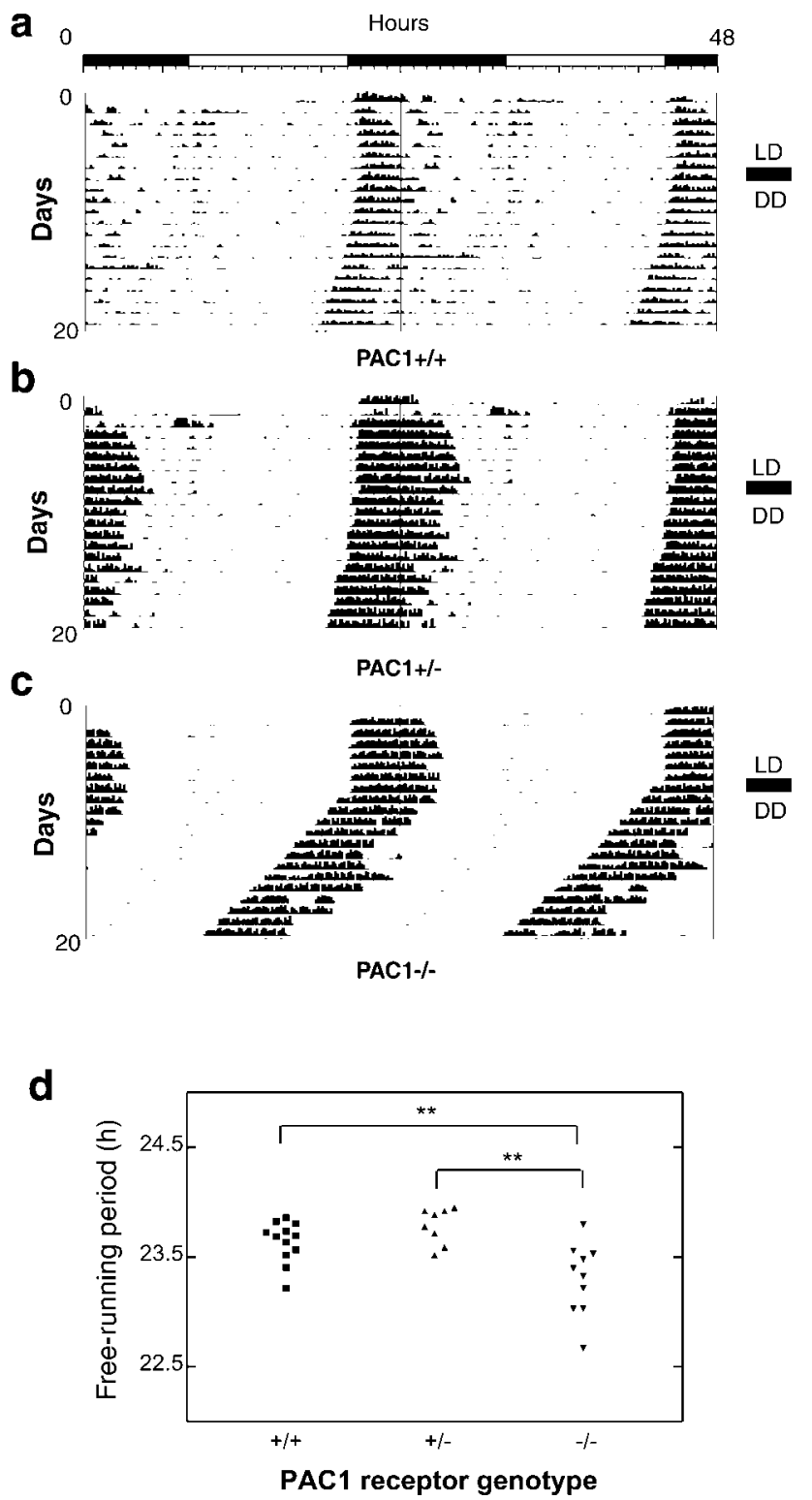

Figure 2. Circadian rhythm of locomotor activity in the $P A C 1$ genotype mice. Wheel-running activity was double-plotted according to the convention so that the data for each day are represented both to the right and beneath that of the previous day. Mice maintained in a $12 \mathrm{hr}$ LD cycle (indicated by the top black-white bar) were placed in constant darkness $(D D)$ conditions on the day indicated by the black bar to the right in each figure. Free-running period of locomotor activity in DD is exemplified by representative free-running actograms of wild-type $(a), P A C 1^{+/-}(b)$, and $P A C 1^{-/-}$animals $(c)$. The calculated free-running periods for each animal of the different genotypes in DD are shown in $d$. In constant darkness, the free-running period $(\tau)$ was significantly shortened in $P A C 1^{-/-}$mice compared with wild-type $\left({ }^{* *} p<0.01\right.$, Mann-Whitney $U$ test).

gene expression within the SCN of wild-type and $P A C 1^{-1-}$ animals examined at midsubjective day. At this time point per gene expression level was uniformly high in the entire SCN (CT6, data not shown).

\section{Photic stimulation at early night}

We next examined the effect of exposure to a 30 min light pulse at early night when light is known to induce phase delay (CT16) of the circadian rhythm in mice (Daan and Pittendrigh, 1976a).
$P A C 1^{-1-}$ mice showed a significantly larger phase delay in locomotor activity compared with the wild-type mice at CT16 $(116.0 \pm 18.8$ vs $96.3 \pm 10.3 \mathrm{~min})$ (Figs. 3, 4a, 6). The behavior of $P A C 1^{+/-}$mice and wild-type mice was identical, and the heterozygous mice were not investigated further (Figs. $4 a, 5 a$ ).

Because of the anatomical and temporal specificity of expression, the immediate-early gene c-fos has been suggested to be a molecular component of the photic pathway for entrainment of the circadian clock (Rusak et al., 1990). It has been used as a functional marker for the activation of SCN neurons by light and the distinct induction of both mRNA and protein within the retinorecipient (ventrolateral) subdivision of the SCN (Schwartz et al., 1994, 2000; Kornhauser et al., 1996). In both wild-type and $P A C 1^{-1-}$ mice, the level of c-fos and per gene expression was uniformly low in the entire SCN at night (Figs. 4, 5). In wild-type mice, light increased the level of c-fos mRNA in the retinorecipient $\mathrm{SCN}$, whereas in $P A C 1^{-/-}$mice the c-fos response was almost completely blunted (Fig. $4 b$ ). The clock gene mPerl is light-inducible at early night and has been associated with lightinduced changes in running wheel activity at night (Albrecht et al., 1997; Shigeyoshi et al., 1997; Zylka et al., 1998; Akiyama et al., 1999; Field et al., 2000). Consequently, we examined the gene expression of $m P e r l$ in the SCN of wild-type and $P A C 1$ receptordeficient mice. As previously reported, mPer1 gene expression was induced in the retinorecipient zone of wild-type animals within $1 \mathrm{hr}$ after exposure to a 30 min light pulse (Albrecht et al., 1997; Shigeyoshi et al., 1997; Zylka et al., 1998) (Fig. 4c). In contrast, the light-induced increase in mPerl gene expression was abolished in $\mathrm{PACl}^{-1-}$ mice, as found for c-fos (Fig. 4b,c). As previously reported, light stimulation in the wild-type mice (Albrecht et al., 1997) at ZT16 also induces mPer 2 expression within $1 \mathrm{hr}$. As seen for mPer1, light-induced mPer2 expression was significantly blunted in $P A C 1^{-1-}$ mice compared with wild-type animals at this time point (Fig. $4 d$ ).

\section{Photic stimulation at late night}

Thirty minute light pulse at late subjective night provoked a marked difference in behavior between the wild-type and the $P A C 1^{-1-}$ mice. Light induced a $36.9 \pm 4.3 \mathrm{~min}$ phase advance in the wild-type mice well in accord with previous reports on mice (Daan and Pittendrigh, 1976a). In contrast, a $60.0 \pm 28.2 \mathrm{~min}$ phase delay in locomotor activity was observed in $P A C 1^{-/-}$mice (Figs. $3 b, 5 a, 6)$. A full PRC performed in three wild-type and three $P A C 1^{-1-}$ animals excluded that the phase response to light in $P A C 1^{-1-}$ mice was attributable to a shift of the PRC to the right (Fig. 6). At late subjective night, a $30 \mathrm{~min}$ light pulse induced $c$-fos and mPer1 gene expression in the ventrolateral part of the SCN to the same level in wild-type and $P A C 1^{-/-}$mice within 1 hr (Fig. 5b,c), indicating a $P A C 1$ receptor-independent mechanism is involved in the light-induced expression of these two genes at late night. Light stimulation at late night did not induce $m P e r 2$ expression in the wild-type animals in agreement with previous observation (Albrecht et al., 1997). A slight but statistically significant decrease in mPer 2 expression was, however, demonstrated in $P A C 1^{-/-}$mice compared with the wild-type animals (Fig. 5d).

\section{DISCUSSION}

Light entrainment of the clock to the environmental light/dark cycle is believed to involve induction of c-fos expression (Kornhauser et al., 1996) and the recently identified clock genes Per1 and Per2 (Albrecht et al., 1997; Shigeyoshi et al., 1997; Zylka et 
Table 1. Expression of mPer1 and mPer2 genes in the SCN of wild-type and $\mathrm{PAC1}^{-/-}$mice kept in a 12 hr light/dark cycle

\begin{tabular}{|c|c|c|c|c|}
\hline \multirow[b]{2}{*}{ Zeitgeber } & \multicolumn{2}{|c|}{ mPer1 (dpm/gm) } & \multicolumn{2}{|c|}{ mPer2 (dpm/gm) } \\
\hline & Wild-type & $\mathrm{PAC1}^{-/-}$ & Wild-type & $\mathrm{PAC}^{-/-}$ \\
\hline ZT6 & $110.3 \pm 15.6$ & $120.0 \pm 10.1$ & $33.9 \pm 6.4$ & $23.8 \pm 7.6$ \\
\hline ZT17 & $34.4 \pm 3.9$ & $36.4 \pm 3.6$ & $11.1 \pm 1.0$ & $21.1 \pm 3.2$ \\
\hline ZT24 & $39.4 \pm 5.1$ & $55.8 \pm 5.2^{*}$ & $34.2 \pm 2.8$ & $33.1 \pm 5.4$ \\
\hline
\end{tabular}

Values are means \pm SEM; $n=6-8$.

${ }^{*} p<0.05$ (Mann-Whitney $U$ test).

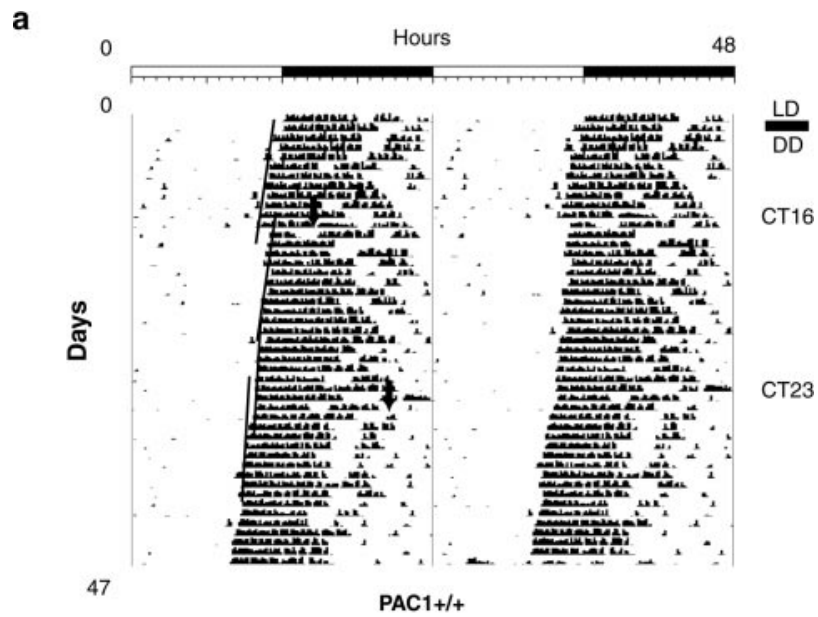

b

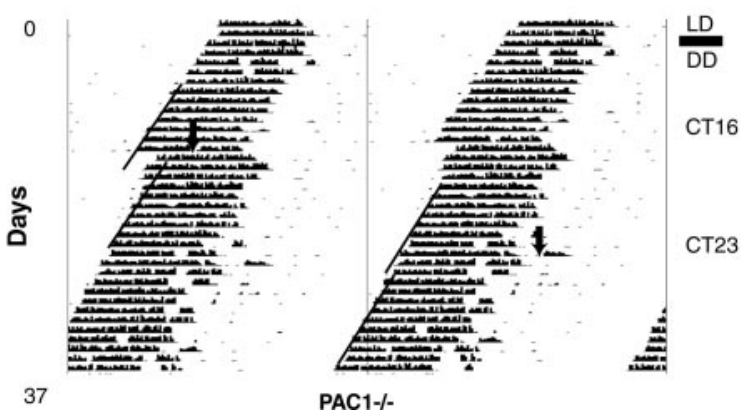

Figure 3. The effects of a 30 min light pulse on the circadian phase at two different circadian times (CT16 and CT23) in wild-type and $P A C 1^{-1-}$ animals kept in constant darkness. Wheel-running activity was doubleplotted according to the convention so that the data for each day are represented both to the right and beneath that of the previous day. Representative free-running actograms from wild-type $(a)$ and $P A C 1^{-1-}$ animals $(b)$ are shown. The animals were maintained in a $12 \mathrm{hr}$ LD cycle, as indicated by the top black-white bar and subsequently placed in constant darkness $(D D)$ conditions on the day indicated by the black bars to the left in each figure. Light pulses indicated (by arrows) at the two different time points (CT16 and CT23) were given with at least a $10 \mathrm{~d}$ interval. Steady-state phase shifts (in minutes) were determined by the drawn eye-fitted lines.

al., 1998; Akiyama et al., 1999; Yan et al., 1999; Field et al., 2000). These genes are rapidly induced by light stimulation at early and late subjective night in the retinorecipient (ventrolateral) zone of the SCN followed by a phase delay and/or phase advance in the behavioral rhythm, respectively (Meijer and Rietveld, 1989). In the present study we have shown that mice lacking the PAC1 receptor respond to light stimulation at early night by larger phase delays in behavioral rhythm compared with wild-type mice, in addition to a marked reduction in light-induced mPerl, mPer2, and c-fos gene expression in the retinorecipient zone of the SCN. This dissociation between light-induced phase shift of running wheel activity and induction of c-fos, Perl, and Per2 gene expression in the SCN indicates that light-induced c-fos and clock gene expression and phase shift are not always interdependent phenomena. The role of c-fos gene expression in the SCN in circadian rhythm regulation is not fully clarified. c-fos gene expression in the SCN has been correlated with circadian function because of the anatomical specificity of light-induced gene expression within the retinorecipient zone of the SCN, circadian phase dependence of both c-fos induction and phase-shifting behavior, and because photic thresholds of the two processes are quantitatively correlated (Kornhauser et al., 1990). There is, however, no perfect relation between light-induced expression of c-fos and phase shift of circadian rhythms, and examples of phase shift of the behavioral rhythm without induction of c-fos exist. The lack of correlation is particularly apparent at the transition between the delay and the advanced periods, time spans during which light induces c-fos gene expression to a maximum but does not alter circadian activity rhythms (Sutin and Kilduff, 1992). In transgenic hypertensive TGR (mRen2) 27 rats, light phase shifts the activity rhythm without induction of c-fos (Lemmer et al., 2000). Furthermore, c-fos knock-out mice were still able to respond to light pulses, although they showed a damped phase-response curve (Honrado et al., 1996). Together with the present data showing that light-induced c-fos expression in the $\mathrm{SCN}$ of $P A C 1^{-/-}$mice was completely blunted at early night, light-induced c-fos expression may be involved but is not necessary for light-induced phase shift of the behavioral rhythms at this time point. Moreover, $P A C 1$ receptor activation seems necessary for light-induced c-fos expression at early night.

Interestingly, the recently identified clock genes mPerl and mPer2, which have been implicated in photic responses at night (Albrecht et al., 1997; Shigeyoshi et al., 1997; Zylka et al., 1998; Akiyama et al., 1999; Field et al., 2000) did not, like c-fos, increase after light stimulation at early night in $P A C 1^{-1-}$ mice despite the larger phase delay. At late night when photic stimulation provoked a phase delay in $P A C 1^{-/-}$mice in contrast to a phase advance in wild-type, $m P e r l$, and $c$-fos gene expression of $P A C 1^{-1-}$ mice was similar to the wild type. This indicates that $P A C 1$ receptor signaling plays a minor if any role in light-induced gene expression of mPerl and c-fos gene at this time point. Perl gene expression has been linked to light-induced phase shifts because of (1) a rapid (30-60 min) and robust induction of Per1 mRNA in the ventrolateral zone of the SCN (Shigeyoshi et al., 1997), (2) a correlation between light-induced Per1 expression and light-induced phase shift (Shigeyoshi et al., 1997), and (3) blocking of light-induced phase shift with antisense oligonucleotides to Per1 mRNA (Akiyama et al., 1999). A possible role of Per2 in photic phase shifting at early night is suggested because of 
a

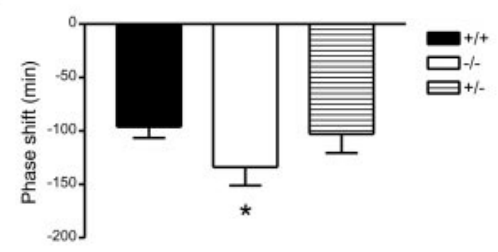

b
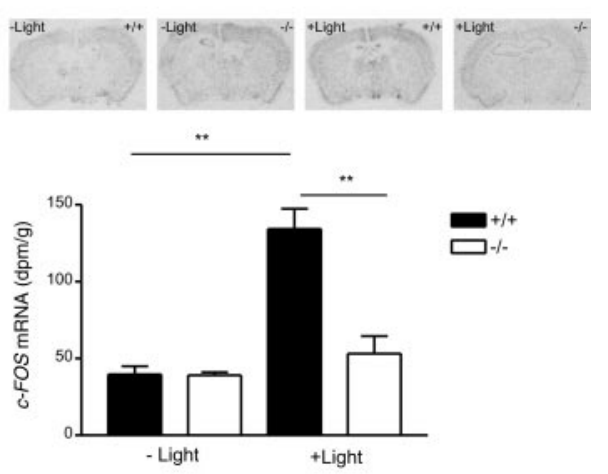

C
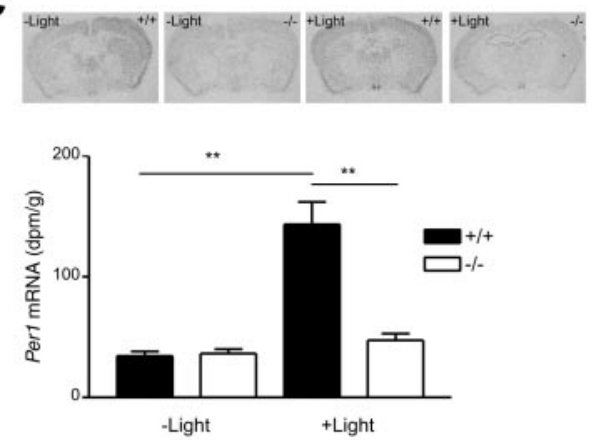

d
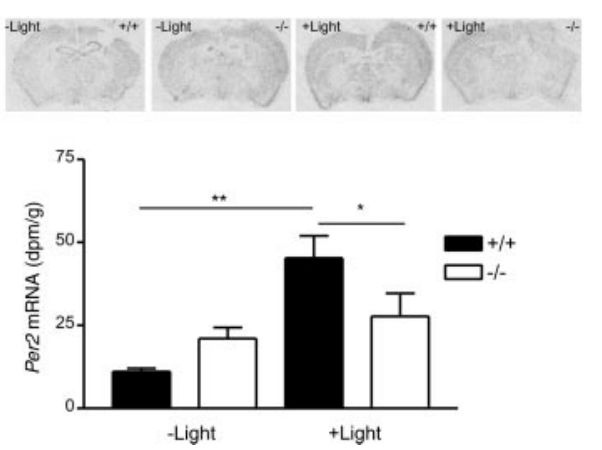

Figure 4. The effects of photic stimulation at early subjective night. A 30 min light pulse (>300 lux) administered at CT16 caused a phase shift of the circadian rhythm $(a)$ and gene expression of c-fos $(b), \operatorname{mPer} 1(c)$, and $m P e r 2(d)$ in the SCN of wild-type, $P A C 1^{+/-}$(only in $a$ ) and $P A C 1^{-/-}$ mice. Representative in situ hybridization signals for c-fos, mPerl, and $m P e r 2$ in the SCN at each time point are shown on the top of each panel. Note the increased phase delay observed in $P A C 1^{-1-}$ mice compared with wild-type animals and the blunted light response of c-fos, mPerl, and $m P e r 2$ gene expression in $P A C 1^{-1-}$ mice. Values are given as means \pm $\operatorname{SEM}\left(n=6-8\right.$ animals). ${ }^{*} p<0.05 ;{ }^{* *} p<0.01$ (Mann-Whitney $U$ test). the light-induced stimulation of Per2 mRNA in the same part of the SCN as seen for Perl at this time (Albrecht et al., 1997; Takumi et al., 1998). The present study clearly demonstrates that $P A C 1^{-1-}$ mice are able to phase shift without induction of Perl and with a blunted Per 2 mRNA expression in the ventrolateral part of the SCN at early night. $P A C 1$ receptor signaling seems important for light-induced Per gene regulation, and the results suggest that other factors are important for light-induced phase shift of the behavioral rhythm.

The lack of $P A C 1$ receptor signaling seems to affect the rhythmic expression of the Perl genes. During LD condition mPerlgene expression showed a slight but statistically significant increase at dawn, whereas $m P e r 2$ was similar in both wild-type and $P A C 1^{-1-}$ mice, suggesting that in $P A C 1^{-1-}$ mice the molecular machinery regulating $m P e r 1$ entrainment could be disturbed. During constant darkness, $P A C 1^{-/-}$mice had a significant shortened $\tau$ compared with wild-type animals, supporting the notion that $P A C 1$ receptor signaling participates in the regulation of the core clock elements controlling the $\tau$. As previously reported in mice (Shigeyoshi et al., 1997) and rats (Yan et al., 1999), the expression level of the mRNA of mPer at midsubjective day was uniformly high throughout the ventrolateral and dorsomedial SCN in wild-type and $P A C 1^{-/-}$animals (data not shown), indicating that circadian expression of the per genes takes place in the same subregions of the SCN of both wild-type and $P A C 1^{-1-}$ animals.

It remains to be investigated whether other components of the molecular "clock" are changed in $P A C 1^{-/-}$mice. The first identified mammalian clock gene, clock (Antoch et al., 1997; King et al., 1997) has been shown to influence the regulation of light sensitivity of the clock. Clock mutants had a blunted expression of both c-fos, Per1, and Per2 in the SCN after light stimulation at night (Shearman and Weaver, 1999), although these mice were able to entrain to light (Antoch et al., 1997; King et al., 1997). Also the cryptochromes CRY1 and CRY2, which are parts of the molecular clock (van der Horst et al., 1999; Vitaterna et al., 1999), showed changed light-induced Per expression at night (Okamura et al., 1999). In CRY2-deficient mice, light-induced Per1 expression is reduced $50-60 \%$, whereas the light-induced phase shift (6 hr light stimulation) was increased compared with wild-type animals (Thresher et al., 1998). In CRY1-lacking mice, lightinduced Per 1 expression is blunted, but Per 2 expression is normal (Vitaterna et al., 1999). Future studies will clarify whether the $\mathrm{CRY}$ and/or the clock genes could be target for $P A C 1$ receptor signaling.

Glutamate is considered to be the primary transmitter mediating light information to the clock (Ding et al., 1994; Ebling, 1996). There is, however, increasing evidence that PACAP, which is costored with glutamate in the RHT (Hannibal et al., 2000), participates in photic entrainment of the clock (Kopp et al., 1997, 1999; von Gall et al., 1998; Harrington et al., 1999; Chen et al., 1999). However, the changes in rhythms observed in the PAC1 receptor-deficient mice were not predictable from previous studies, all performed in "acute" models. In vitro and in vivo application of glutamate or NMDA induce phase delay of the endogenous rhythm at early night similar to light (Ding et al., 1994; Mintz and Albers, 1997; Mintz et al., 1999). In vitro application of PACAP in micromolar concentration increases the glutamateinduced phase delay (Chen et al., 1999), whereas nanomolar concentration of PACAP alone induces a phase shift similar to that observed for glutamate (Harrington et al., 1999). The present data indicate that the $P A C 1$ receptor in the $\mathrm{SCN}$ is 

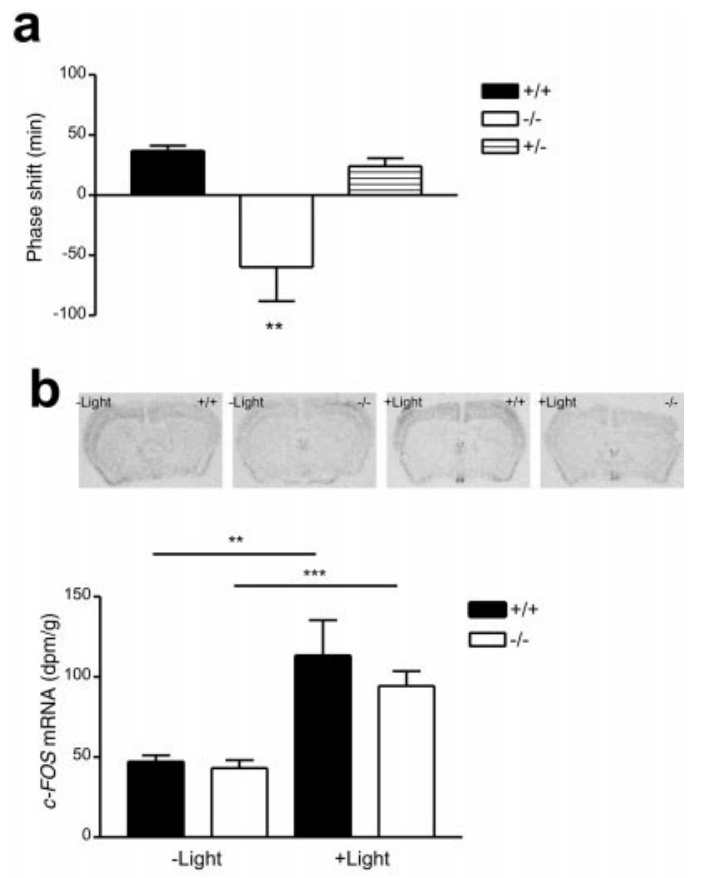

c
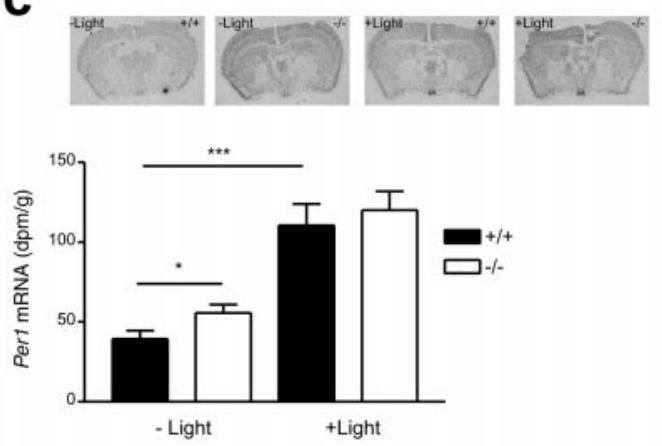

d

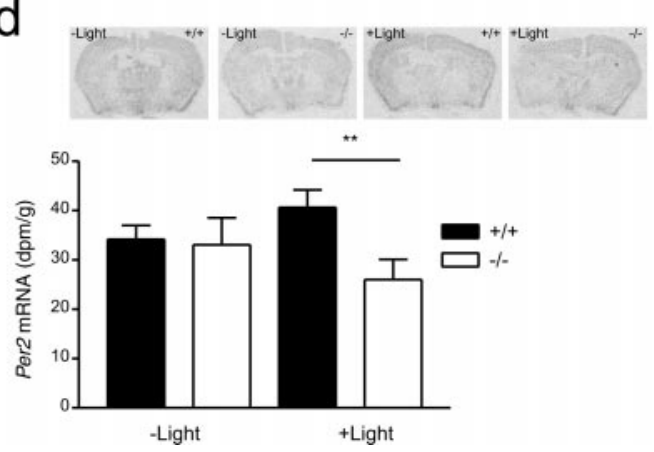

Figure 5. The effects of photic stimulation at late subjective night. A 30 min light pulse (>300 lux) administrated at CT23 causes a phase shift of the circadian rhythm $(a)$ and gene expression of c-fos $(b)$, mPerl $(c)$, and $m P e r 2(d)$ in the SCN of wild-type, $P A C 1^{+/-}$(only in $a$ ) and $P A C 1^{-1-}$ mice. Representative in situ hybridization signals for c-fos, mPerl, and $m P e r 2$ in the SCN at each time point are shown on the top of each panel. Note the phase delay observed in $P A C 1^{-1-}$ mice compared with a phase advance seen in wild-type animals and the light-induced inhibition of $m P e r 2$ gene expression in $P A C 1^{-1-}$ mice. Values are given as means \pm SEM $\left(n=6-8\right.$ animals). ${ }^{*} p<0.05 ; * * p<0.01$; *** $p<0.001$ (MannWhitney $U$ test).

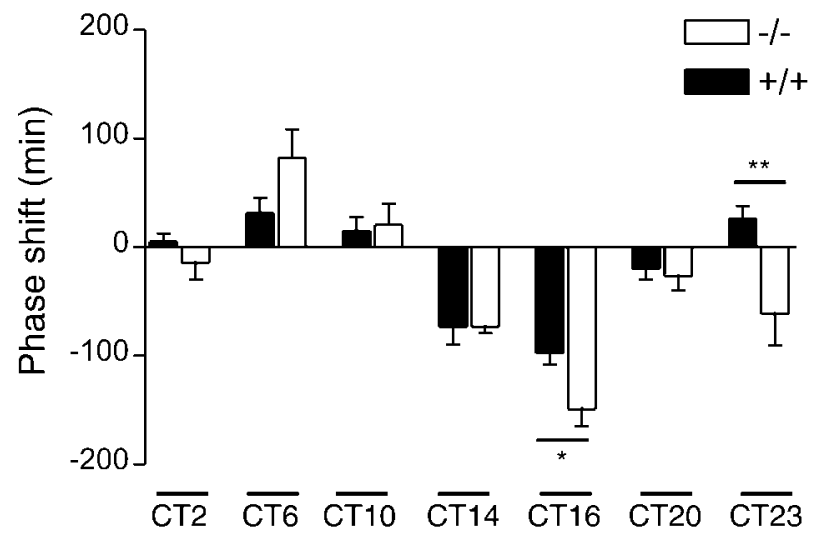

Figure 6. Phase-dependent effects on running wheel activity (PRC) to a 30 min light pulse (>300 lux) given to $P A C 1^{+/+}$and $P A C 1^{-/-}$kept in constant darkness. CT12 represents the time point for activity onset. Values (mean \pm SEM, $n=3$ for all CTs except CT16 and CT23 where $n=7-9$ ) are given in minutes. Positive values represent a phase advance, and negative values represent a phase delay of activity rhythm. ${ }^{*} p<0.05$, ${ }^{* *} p<0.01$, Mann-Whitney $U$ test.

involved in the light-induced phase shift at night. The larger phase delay after light stimulation in the behavioral rhythm of $P A C 1^{-1-}$ mice compared with wild-type animals suggests that the clock sensitivity to light is increased when the $P A C 1$ receptor system is missing. The changed light responsiveness at night is most likely caused by compensatory changes in $P A C 1$ receptordeficient mice. We have previously shown that the cAMP-PKA pathway is responsible for the PACAP effects during subjective day (Hannibal et al., 1997), and there is accumulating evidence that both CAMP-PKA and calcium-dependent pathways via $\mathrm{PKC} / \mathrm{IP}_{3}$ are involved in the PACAP-mediated effects at night (von Gall et al., 1998; Kopp et al., 1999; Tischkau et al., 2000). Interestingly, application of a specific PKA inhibitor, KT5720, blocks glutamate-induced Per1 mRNA expression in the SCN at early, but not at late, night (Tischkau et al., 2000). This finding accords well with a glutamate-PACAP interaction via the PAC1 receptor and cAMP-PKA signaling (Tischkau et al., 2000). PAC1 receptor activation was recently shown to release calcium from ryanodine-caffeine stores independent of inositol trisphosphates and cAMP pathways in bovine adrenal medullary cells (Tanaka et al., 1998). Although it remains to be shown the existence of such pathway within the SCN, it is not unlikely because lightinduced phase shift at early night is dependent on the release of intracellular calcium via ryanodine receptor activation (Ding et al., 1998). The phase response to light stimulation is clockcontrolled and dependent of the $\tau$ (Daan and Pittendrigh, 1976b; Ding et al., 1994). The mechanism that determines the direction of the phase shift is not known but it seems to be dependent on the properties of the molecular clock (Dunlap, 1999; King and Takahashi, 2000). This mechanism seemed to be changed in $P A C 1^{-1-}$ mice resulting in a light-induced phase delay in contrast to the phase advance in wild-type mice at late night. How $P A C 1$ receptor signaling participates in this regulation is unknown. Interestingly, application of an adenosine $\mathrm{A}_{2 \mathrm{~A}}$ receptor agonist directly into the SCN at CT20 followed by a 15 min light pulse causes a phase delay similar to that observed in $\mathrm{PAC1}^{-/-}$ mice (Mintz and Albers, 2000). A fine-tuning role of adenosine receptor activation in synaptic transmission has been shown to involve NMDA-receptor signaling and cAMP-PKA activation (Sebastiao and Ribeiro, 2000). Whether these signaling pathways 
are involved in the altered sensitivity to photic stimulation seen in $P A C 1^{-1-}$ mice at late night remains to be examined.

In conclusion, our data indicate that $P A C 1$ receptor signaling participates in the gating control of photic sensitivity of the clock and shows that light-induced phase shift and induction of the clock genes Perl and Per 2 are not always interdependent phenomena, suggesting that other factors are of importance for light-induced phase shifts at night.

\section{REFERENCES}

Akiyama M, Kouzu Y, Takahashi S, Wakamatsu H, Moriya T, Maetani M, Watanabe S, Tei H, Sakaki Y, Shibata S (1999) Inhibition of lightor glutamate-induced mPer1 expression represses the phase shifts into the mouse circadian locomotor and suprachiasmatic firing rhythms. J Neurosci 19:1115-1121.

Albrecht U, Sun ZS, Eichele G, Lee CC (1997) A differential response of two putative mammalian circadian regulators, mper1 and mper2, to light. Cell 91:1055-1064.

Antoch MP, Song E-J, Chang A-M, Vitaterna MH, Zhao Y, Wilsbacher LD, Sangoram AM, King DP, Pinto LH, Takahashi JS (1997) Functional identification of the mouse circadian clock gene by transgenic BAC rescue. Cell 89:655-667.

Arimura A (1998) Perspectives on pituitary adenylate cyclase activating polypeptide (PACAP) in the neuroendocrine, endocrine, and nervous systems. Jpn J Physiol 48:301-331.

Chen D, Buchanan GF, Ding JM, Hannibal J, Gillette MU (1999) PACAP: a pivotal modulator of glutamatergic regulation of the suprachiasmatic circadian clock. Proc Natl Acad Sci USA 96:13409-13414.

Daan S, Pittendrigh CS (1976a) A functional analysis of the circadian pacemakers in nocturnal rodents. IV. Entrainment: Pacemaker and clock. J Comp Physiol 106:253-266.

Daan S, Pittendrigh CS (1976b) A functional analysis of circadian pacemakers in nocturnal rodents. II. The variability of phase response curves. J Comp Physiol 106:253-266.

Ding JM, Chen D, Weber ET, Faiman LE, Rea MA, Gillette MU (1994) Resetting the biological clock: mediation of nocturnal circadian shifts by glutamate and NO. Science 266:1713-1717.

Ding JM, Buchanan GF, Tischkau SA, Chen D, Kuriashkina L, Faiman LE, Alster JM, McPherson PS, Campbell KP, Gillette MU (1998) A neuronal ryanodine receptor mediates light-induced phase delays of the circadian clock. Nature 394:381-384.

Dunlap JC (1999) Molecular bases for circadian clocks. Cell 96:271-290.

Ebling FJ (1996) The role of glutamate in the photic regulation of the suprachiasmatic nucleus. Prog Neurobiol 50:109-132.

Fahrenkrug J, Hannibal J (1998) PACAP immunoreactivity in capsaicinsensitive nerve fibres supplying the rat urinary tract. Neuroscience 83:1261-1272.

Field MD, Maywood ES, O'Brien JA, Weaver DR, Reppert SM, Hastings MH (2000) Analysis of clock proteins in mouse SCN demonstrates phylogenetic divergence of the circadian clockwork and resetting mechanisms. Neuron 25:437-447.

Hannibal J, Mikkelsen JD, Fahrenkrug J, Larsen PJ (1995a) Pituitary adenylate cyclase-activating peptide gene expression in corticotropinreleasing factor-containing parvicellular neurons of the rat hypothalamic paraventricular nucleus is induced by colchicine, but not by adrenalectomy, acute osmotic, ether, or restraint stress. Endocrinology 136:4116-4124.

Hannibal J, Mikkelsen JD, Clausen H, Holst JJ, Wulff BS, Fahrenkrug J (1995b) Gene expression of pituitary adenylate cyclase activating polypeptide (PACAP) in the rat hypothalamus. Regul Pept 55:133-148. Hannibal J, Ding JM, Chen D, Gillette MU, Fahrenkrug J, Larsen PJ, Mikkelsen JD (1997) Pituitary adenylate cyclase activating peptide (PACAP) in the retinohypothalamic tract. A daytime regulator of the biological clock. J Neurosci 17:2637-2644.

Hannibal J, Moller M, Ottersen OP, Fahrenkrug J (2000) PACAP and glutamate are co-stored in the retinohypothalamic tract. J Comp Neurol 418:147-155.

Hannibal J, Vrang N, Card JP, Fahrenkrug J (2001) Light dependent induction of c-Fos during subjective day and night in PACAP containing retinal ganglion cells of the retino-hypothalmic tract. J Biol Rhythms, in press.

Harmar AJ, Arimura A, Gozes I, Journot L, Laburthe M, Pisegna JR, Rawlings SR, Robberecht P, Said SI, Sreedharan SP, Wank SA, Waschek JA (1998) International Union of Pharmacology. XVIII. Nomenclature of receptors for vasoactive intestinal peptide and pituitary adenylate cyclase-activating polypeptide. Pharmacol Rev 50:265-270.

Harrington ME, Hoque S, Hall A, Golombek D, Biello S (1999) Pituitary adenylate cyclase activating peptide phase shifts circadian rhythms in a manner similar to light. J Neurosci 19:6637-6642.

Honrado GI, Johnson RS, Golombek DA, Spiegelman BM, Papaioannou
VE, Ralph MR (1996) The circadian system of c-fos deficient mice. J Comp Physiol [A] 178:563-570.

Jamen F, Persson K, Bertrand G, Rodriguez-Henche N, Puech R, Bockaert J, Ahren B, Brabet P (2000) PAC1 receptor-deficient mice display impaired insulinotropic response to glucose and reduced glucose tolerance. J Clin Invest 105:1307-1315.

Johnson RF, Moore RY, Morin LP (1988) Loss of entrainment and anatomical plasticity after lesions of the hamster retinohypothalamic tract. Brain Res 460:297-313.

King DP, Takahashi JS (2000) Molecular genetics of circadian rhythms in mammals. Annu Rev Neurosci 23:713-742.

King DP, Zhao Y, Sangoram AM, Wilsbacher LD, Tanaka M, Antoch MP, Steeves TDL, Vitaterna MH, Kornhauser JM, Lowry PJ, Turek FW, Takahashi JS (1997) Positional cloning of the mouse circadian clock gene. Cell 89:641-653.

Klein DC, Moore RY, Reppert SM (1991) Suprachiasmatic nucleus: The mind's clock. New York: Oxford UP.

Kopp M, Meissl H, Korf HW (1997) The pituitary adenylate cyclaseactivating polypeptide-induced phosphorylation of the transcription factor CREB (cAMP response element binding protein) in the rat suprachiasmatic nucleus is inhibited by melatonin. Neurosci Lett 227:145-148.

Kopp M, Schomerus C, Dehghani F, Korf HW, Meissl H (1999) Pituitary adenylate cyclase activating polypeptide and melatonin in the suprachiasmatic nucleus: effects on the calcium signal transduction cascade. J Neurosci 19:20619-219.

Kornhauser JM, Nelson DE, Mayo KE, Takahashi JS (1990) Photic and circadian regulation of c-fos gene expression in the hamster suprachiasmatic nucleus. Neuron 5:127-134.

Kornhauser JM, Mayo KE, Takahashi JS (1996) Light, immediate-early genes, and circadian rhythms. Behav Genet 26:221-240.

Lemmer B, Hauptfleisch S, Witte K (2000) Loss of $24 \mathrm{~h}$ rhythm and light-induced c-fos mRNA expression in the suprachiasmatic nucleus of the transgenic hypertensive TGR(mRen2)27 rat and effects on cardiovascular rhythms(1). Brain Res 883:250-257.

Levine JD, Weiss ML, Rosenwasser AM, Miselis RR (1991) Retinohypothalamic tract in the female albino rat: a study using horseradish peroxidase conjugated to cholera toxin. J Comp Neurol 306:344-360.

Lutz EM, Sheward WJ, West KM, Morrow JA, Fink G, Harmar AJ (1993) The VIP2 receptor: molecular characterisation of a cDNA encoding a novel receptor for vasoactive intestinal peptide. FEBS Lett 334:3-8.

Meijer JH, Rietveld WJ (1989) Neurophysiology of the suprachiasmatic circadian pacemaker in rodents. Physiol Rev 69:671-707.

Mintz EM, Albers HE (1997) Microinjection of NMDA into the SCN region mimics the phase shifting effect of light in hamsters. Brain Res 758:245-249.

Mintz EM, Albers HE (2000) Activation of adenosine receptors in the SCN region blocks the phase shifting effects of light and inhibit locomotor activity in Syrian hamsters. Seventh Meeting Society for Research on Biological Rhythms, Jacksonville, FL, October.

Mintz EM, Marvel CL, Gillespie CF, Price KM, Albers HE (1999) Activation of NMDA receptors in the suprachiasmatic nucleus produces light-like phase shifts of the circadian clock in vivo. J Neurosci 19:5124-5130.

Moore RY, Lenn NJ (1972) A retinohypothalamic projection in the rat. J Comp Neurol 146:1-14.

Moore RY, Speh JC, Card JP (1995) The retinohypothalamic tract originates from a distinct subset of retinal ganglion cells. J Comp Neurol 352:351-366.

Nielsen HS, Hannibal J, Moller-Knudsen S, Fahrenkrug J (2001) Pituitary adenylate cyclase activating polypeptide induces period 1 and period 2 gene expression in the rat suprachiasmatic nucleus (SCN) during late night. Neuroscience 103:433-441.

Okamura H, Miyake S, Sumi Y, Yamaguchi S, Yasui A, Muijtjens M, Hoeijmakers JH, van der Horst GT (1999) Photic induction of mPer1 and $\mathrm{mPer} 2$ in cry-deficient mice lacking a biological clock. Science 286:2531-2534

Rusak B, Robertson HA, Wisden W, Hunt SP (1990) Light pulses that shift rhythms induce gene expression in the suprachiasmatic nucleus. Science 248:1237-1240.

Schwartz WJ, Takeuchi J, Shannon W, Davis EM, Aronin N (1994) Temporal regulation of light-induced Fos and Fos-like protein expression in the ventrolateral subdivision of the rat suprachiasmatic nucleus. Neuroscience 58:573-583.

Schwartz WJ, Carpino Jr A, de la Iglesia HO, Baler R, Klein DC, Nakabeppu Y, Aronin N (2000) Differential regulation of fos family genes in the ventrolateral and dorsomedial subdivisions of the rat suprachiasmatic nucleus. Neuroscience 98:535-547.

Sebastiao AM, Ribeiro JA (2000) Fine-tuning neuromodulation by adenosine. Trends Pharmacol Sci 21:341-346.

Shearman LP, Weaver DR (1999) Photic induction of Period gene expression is reduced in Clock mutant mice. NeuroReport 10:613-618.

Shigeyoshi Y, Taguchi K, Yamamoto S, Takekida S, Yan L, Tei H, Moriya T, Shibata S, Loros JJ, Dunlap JC, Okamura H (1997) Light- 
induced resetting of a mammalian circadian clock is associated with rapid induction of the mPer1 transcript. Cell 91:1043-1053.

Spengler D, Waeber C, Pantaloni C, Holsboer F, Bockaert J, Seeburg PH, Journot L (1993) Differential signal transduction by five splice variants of the PACAP receptor. Nature 365:170-175.

Sutin EL, Kilduff TS (1992) Circadian and light-induced expression of immediate early gene mRNAs in the rat suprachiasmatic nucleus. Brain Res Mol Brain Res 15:281-290.

Takumi T, Matsubara C, Shigeyoshi Y, Taguchi K, Yagita K, Maebayashi Y, Sakakida Y, Okumura K, Takashima N, Okamura H (1998) A new mammalian period gene predominantly expressed in the suprachiasmatic nucleus. Genes Cells 3:167-176.

Tanaka K, Shibuya I, Uezono Y, Ueta Y, Toyohira Y, Yanagihara N, Izumi F, Kanno T, Yamashita H (1998) Pituitary adenylate cyclaseactivating polypeptide causes $\mathrm{Ca}^{2+}$ release from ryanodine/caffeine stores through a novel pathway independent of both inositol trisphosphates and cyclic AMP in bovine adrenal medullary cells. J Neurochem 70:1652-1661.

Thresher RJ, Vitaterna MH, Miyamoto Y, Kazantsev A, Hsu DS, Petit C, Selby CP, Dawut L, Smithies O, Takahashi JS, Sancar A (1998) Role of mouse cryptochrome blue-light photoreceptor in circadian photoresponses. Science 282:1490-1494.

Tischkau SA, Gallman EA, Buchanan GF, Gillette MU (2000) Differ- ential cAMP gating of glutamatergic signaling regulates long-term state changes in the suprachiasmatic circadian clock. J Neurosci 20:7830-7837.

van der Horst GT, Muijtjens M, Kobayashi K, Takano R, Kanno S, Takao M, de Wit J, Verkerk A, Eker AP, van Leenen D, Buijs R, Bootsma D, Hoeijmakers JH, Yasui A (1999) Mammalian Cry1 and Cry2 are essential for maintenance of circadian rhythms. Nature 398:627-630.

Vitaterna MH, Selby CP, Todo T, Niwa H, Thompson C, Fruechte EM, Hitomi K, Thresher RJ, Ishikawa T, Miyazaki J, Takahashi JS, Sancar A (1999) Differential regulation of mammalian period genes and circadian rhythmicity by cryptochromes 1 and 2. Proc Natl Acad Sci USA 96:12114-12119.

von Gall C, Duffield GE, Hastings MH, Kopp M, Dehghani F, Korf HW, Stehle JH (1998) CREB in the mouse SCN: A molecular interface coding the phase adjusting stimuli light, glutamate, PACAP, and melatonin for clockwork access. J Neurosci 18:10389-10397.

Yan L, Takekida S, Shigeyoshi Y, Okamura H (1999) Per1 and Per2 gene expression in the rat suprachiasmatic nucleus: circadian profile and the compartment-specific response to light. Neuroscience 94:141-150.

Zylka MJ, Shearman LP, Weaver DR, Reppert SM (1998) Three period homologs in mammals: differential light responses in the suprachiasmatic circadian clock and oscillating transcripts outside of brain. Neuron 20:1103-1110. 